RESEARCH AND PRACTICE

\title{
Sexual health education in Georgia: A role for reducing sexually transmitted infections among adolescents
}

\author{
Madison L. Gates, $\mathrm{PhD}^{1}$, Veronica Walker, MSLS², and Nancy C. Webb, $\mathrm{PhD}^{1}$ \\ ${ }^{1}$ Institute of Public and Preventive Health, Georgia Regents University, Augusta, GA; ${ }^{2}$ Lexington Public Library System, Lexington, KY
}

\begin{abstract}
Background: In Georgia, sexually transmitted infections (STIs) are a substantial health issue, particularly among young adults in vulnerable and minority populations. The United States Preventive Services Task Force recommends that sexually active adolescents and at-risk adults receive behavioral counseling and education in primary care settings, community organizations, departments of health, and schools
\end{abstract}

Methods: The present approach used in Georgia for educating adolescents at high risk for STIs about these diseases was assessed. The data collected included standards for sexual health education, survey results from educators and students, and observations from a pilot study with adolescents detained by the juvenile justice system.

Results: In Georgia, most health educators for middle (87.3\%) and high (93.8\%) schools have health and/or physical education backgrounds. They indicated a need for further education about STIs. For grades 6-12, 24\% of students reported that they had not received HIV/AIDS education during the academic year. Preliminary observations from a study with juvenile detainees indicate that this population has limited knowledge about STIs, their effects and modes of transmission.

Conclusion: Sexual health education, including that for HIV/AIDS, is essential to curtail the STI crisis, and educational endeavors should be culturally sensitive and evidence-based. In Georgia, many citizens, including teachers, are not adequately equipped to make informed decisions regarding STI risk. Georgia, home to the Centers for Disease Control and Prevention, is in a unique position to adapt evidence-based sexual health interventions for its population.

Keywords: adolescent, African Americans, health educators, sex education, sexually transmitted infection, young adult

\section{INTRODUCTION}

In Georgia, sexually transmitted infections (STIs) are a substantial health issue, particularly among young adults in vulnerable and minority populations (Reif et al., 2014; "Vital signs: HIV testing and diagnosis among adults-United States, 2001-2009, 2010; Zhang et al., 2014). Data from 2013 indicate that Georgia leads the United States for rates of primary and secondary syphilis and ranks eighth and ninth for gonorrhea and chlamydia respectively (Braxton et al., 2014). Rates for gonorrhea and chlamydia are particularly high among young African American women (15 - 19 years old). In 2013, these young women in the United States had the second highest rate for gonorrhea $(1,768.5$ per 100,000$)$ across race, gender and other age groups (Braxton et al., 2014). The rate of gonorrhea for young African American women was more than four times that for all African American women (409.2 per 100,000) and more than seventeen times the rate for all females (102.4 per 100,000) (Braxton et al., 2014). Findings for chlamydia (2013) also show a disparity between young African American women and other race, gender and age groups. Young African American women are disproportionately infected with chlamydia, having a rate of 6,907.6 per 100,000 compared to a rate of $1,491.7$ per 100,000 for all African American women and 623.1 per 100,000 for all females (Braxton et al., 2014).
Rates for gonorrhea and chlamydia among adolescent and adult women who have been detained and incarcerated exceed those for their peers who have not been involved with the justice system (Braxton et al., 2014; Herrman \& Waterhouse, 2012; Rosenberg et al., 2014). In 2011, for women entering adult corrections facilities in the U.S., the rate of testing positive for chlamydia was 11 times higher than the incidence in the general female population (Fasula et al., 2013). There is a strong relationship between female populations with detention (adolescents) and incarceration (adults) histories and risk factors, such as having multiple sex partners, engaging in sex while high on drugs and alcohol, using condoms inconsistently (Danielson et al., 2014; Herrman \& Waterhouse, 2012; Morrison-Beedy et al., 2013) and exchanging sex for money (Herrman \& Waterhouse, 2012). The health effects of gonorrhea and chlamydia are well known; untreated infections may result in pelvic inflammatory disease, infertility, and ectopic pregnancy (LeFevre, 2014b). Gonorrhea and chlamydia infections are also associated with increased risk for human immunodeficiency virus (HIV) infection (DiClemente et al., 2014; LeFevre, 2014b). Further, untreated chlamydia infections may contribute to premature births for pregnant women, and may be transmitted to newborns (LeFevre, 2014b). 
STIs, in addition to their health consequences, cost approximately $\$ 16$ billion annually with chlamydia having an annual expense of \$516.7 million and gonorrhea \$162.1 million (LeFevre, 2014b). These expenses translate to an average of \$364 per case for chlamydia and \$354 for gonorrhea (LeFevre, 2014b). In response to the prevalence and cost of gonorrhea and chlamydia, particularly among young women, the United States Preventive Services Task Force (USPSTF) updated its screening recommendations for sexually active women 24 years old and younger and at-risk older women (LeFevre, 2014b). In particular, the USPSTF recommended screenings for populations with the following risk factors: multiple sex partners, inconsistent condom use and commercial sex work (LeFevre, 2014b). Risk factors for gonorrhea and chlamydia are found more often among detained and incarcerated populations than those without justice system involvement. The USPSTF also recommends that sexually active adolescents and at-risk adults receive behavioral counseling (e.g., knowledge about STIs and their transmission) in primary care settings, community organizations, departments of health and schools (LeFevre, 2014a).

\section{Combatting Sexually Transmitted Infections}

Behavioral counseling, and more broadly, education about STIs, including HIV, human sexuality, and reproductive health are mechanisms to inform the populations most atrisk of acquiring these diseases (e.g., adolescent females, African Americans, and young women with a juvenile detention history). Further, STI behavioral counseling and education have the potential to reduce rates and cases of gonorrhea and chlamydia among these populations. Comprehensive and evidence-based sex education are effective in increasing adolescents' knowledge about gonorrhea and chlamydia, providing information about risk reduction and improving self-efficacy to engage in protective behaviors (e.g., using condoms and refusing sex) (Borawski et al., 2015; Fonner, Armstrong, Kennedy, O'Reilly, \& Sweat, 2014; In-Iw, Braverman, Bates, \& Biro, 2015).

\section{Georgia and Sexual Health Education}

Research findings in regard to behavioral counseling and education have shifted the approach to sex education. A focus on evidence is a change from the abstinence approach prevailing between 1998 and 2009, which primarily and sometimes exclusively had a curriculum advocating no sexual contact outside of marriage (Schalet et al., 2014). Abstinence-centric programs were not only ineffective and factually incorrect, but also counterproductive to their goal of minimizing adolescent pregnancies and health problems, such as STIs (Ballonoff Suleiman, Johnson, Shirtcliff, \& Galvan, 2015; Schalet et al., 2014; Stanger-Hall \& Hall, 2011). Since 1998, Georgia has mandated sex education and HIV/AIDS prevention, but the law defines sex education broadly and allows extensive decision-making at the local level (Sex education and AIDS prevention instruction, 1998). The Georgia Department of Education has adopted National Health Education Standards and has defined sexual health elements for three of the seven standards, as shown in Table 1 (Cox, 2010).

\begin{tabular}{|c|c|}
\hline Standard & Example of element \\
\hline $\begin{array}{l}\text { 1. Students will comprehend concepts related to health } \\
\text { promotion and disease prevention to enhance health. }\end{array}$ & $\begin{array}{l}\text { - Compare and contrast local data versus national } \\
\text { data on HIV infections among teens and young } \\
\text { adults. } \\
\text { - Identify personal health risks of engaging in } \\
\text { unprotected sex. }\end{array}$ \\
\hline $\begin{array}{l}\text { 4. Students will demonstrate the ability to use } \\
\text { interpersonal communication skills to enhance health } \\
\text { and avoid or reduce health risks. }\end{array}$ & $\begin{array}{l}\text { Discuss how to communicate clear limits on } \\
\text { sexual behaviors. }\end{array}$ \\
\hline $\begin{array}{l}\text { 5. Students will demonstrate the ability to use decision- } \\
\text { making skills to enhance health. }\end{array}$ & $\begin{array}{l}\text { - Describe the steps individuals should take if } \\
\text { they suspect they have contracted a sexually } \\
\text { transmitted infection (STI). } \\
\text { Discuss the reason(s) abstinence is the most } \\
\text { effective and healthy means for preventing } \\
\text { sexually transmitted infections (STIs). } \\
\text { - Analyze risks and consequences of early sexual } \\
\text { involvement. }\end{array}$ \\
\hline
\end{tabular}

Although sex education by the Georgia Department of Education may not be guided by the abstinence-only approach, the state's Division of Family \& Children Services encourages and financially supports abstinence education (Georgia Division of Family and Children Services, 2015) and elements for the standards explicitly include abstinence (Cox, 2010). Sexual health education and counseling in the broadest sense of the term (i.e., knowledge about STIs, risk and protective behaviors, sexuality, and reproductive health), however, have not been consistently conducted by those with expertise in the area (Barr et al., 2014; Borawski et al., 2015), lack teaching standards, are not exclusively guided by evidence (Barr et al., 2014), and have varying outcomes depending upon the population (i.e., education and counseling programs have not accounted for social, gender, and sexual identity differences across groups) (Ma, Fisher, \& Kuller, 2014; Schalet et al., 2014). 
Concerns regarding expertise and teaching standards are reflected in the most current report for school health profiles, published by the Georgia Department of Human Services (Falb, Figueroa, \& Kanny, 2007). Most of Georgia's health educators for middle (87.3\%) and high (93.8\%) schools have health and/or physical education backgrounds; many of these educators have indicated that they need further education in STI/HIV prevention and human sexuality (Table 2). The need for staff development also may be a factor for sexual health education, given that $34.4 \%$ of middle and $30.3 \%$ of high school courses are delivered by non-health educators (Table 2).

\begin{tabular}{|l|c|c|c|c|}
\hline \multirow{2}{*}{ Table 2. Health Educators and Sexual Health Education (Falb et al., 2007) } \\
\cline { 2 - 5 } & \multicolumn{2}{c|}{ Middle } & \multicolumn{2}{c|}{ High } \\
\cline { 2 - 5 } & $\mathbf{\%}$ & CI $^{\text {* }}$ & \% & CI \\
\hline Health educators & & & & \\
\hline District health education or curriculum coordinator & 48.9 & $40.7-57.1$ & 46.4 & $37.9-54.8$ \\
\hline \multicolumn{1}{|c|}{ Health educator professional preparation } & & & & \\
\hline Health and physical education & 81.9 & $74.6-87.4$ & 84.5 & $76.2-90.2$ \\
\hline Physical education & 5.4 & $2.7-10.7$ & 9.3 & $4.9-17.1$ \\
\hline Biology & 5.1 & $2.4-10.5$ & 1.1 & $0.1-7.3$ \\
\hline Public health & 2.0 & $0.6-6.2$ & 1.7 & $0.4-6.7$ \\
\hline Nursing & 1.4 & $0.4-5.7$ & 2.5 & $0.8-7.4$ \\
\hline \multicolumn{1}{|c|}{ Request for staff development by topic } & & & & \\
\hline HIV prevention & 71.3 & $63.2-78.2$ & 71.1 & $62.1-78.8$ \\
\hline STD prevention & 66.0 & $57.4-73.7$ & 72.4 & $63.4-79.9$ \\
\hline Human sexuality & 61.4 & $53.2-69.0$ & 68.9 & $60.0-76.7$ \\
\hline *95\% Confidence Interval & & & & \\
\hline
\end{tabular}

Improving Student Knowledge about Sexually Transmitted Infections

Sexual health education in Georgia is further problematic, since $32.1 \%(188,629$ of 587,043$)$ of students in grades 6 12 who were surveyed reported that they had not received HIV/AIDS education in the previous year (Barge, 2014). Of students in the twelfth grade, $46.6 \%(29,599$ of 63,481 responded that they had not received HIV/AIDS education in the previous year (Barge, 2014). There appears to be no gender disparity in terms of female and male students in grades $6-12$. Of those who responded, $32.5 \%$ of males $(97,279$ of 299,057$)$ and $31.7 \%$ of females $(91,350$ of 287,986) indicated that they had received no HIV/AIDS education in the previous year (Barge, 2014).

Investigators are surveying adolescent females who are detained by the juvenile justice system about their knowledge of STIs and effects on their health. Those being surveyed are housed at a regional youth detention center, which is a short-term facility for adolescents who are committed for less than a year for less-serious offenses and the population awaiting assignment to a long-term facility (i.e., a youth development campus).

The data emerging from this pilot study are concerning, since 21 of 26 participants (81\%) who are 13-18 years old responded incorrectly to 7 of 12 questions about STIs. Despite the lack of knowledge among these detainees, correctional facilities provide a good venue for interventions (Fasula et al., 2013).
The preliminary findings regarding knowledge about STIs in a juvenile justice population, survey results from nondetained students, the desire of health educators for further information, and Georgia's rank for gonorrhea and chlamydia indicate a need for our state to do more to educate youth, in terms of risk reduction behaviors (e.g., abstinence, self-efficacy to refuse sex) and knowledge about STIs, including their health effects and modes of transmission.

Various evidence-based interventions can provide guidance for policy makers in Georgia as they evaluate the present sexual health education programs, particularly their effectiveness among minority (e.g., African American adolescents and young adults) and vulnerable (e.g., juveniles and adults who have been detained or incarcerated) populations.

Project SAFE (Serostatus Approach to Fighting the HIV Epidemic), was developed by the Centers for Disease Control and Prevention (CDC). One goal of Project SAFE is to support safer sex behavior by HIV-infected individuals. Project SAFE aims to enhance understanding of disease transmission, minimize risk, and present the advantages of behavioral modification (Fasula et al., 2013). When provided in small group venues, Project SAFE is effective in reducing STIs and risky sexual behaviors (Fasula et al., 2013).

Project POWER is a risk reduction curriculum developed and piloted for HIV-negative women serving short sentences in two North Carolina Department of Corrections 
facilities and was adapted from Project SAFE (Fasula et al., 2013). Formative assessment emerging from the piloted curriculum suggested that incarcerated women have multiple risk factors that synergistically increase the likelihood of engaging in risky sexual behaviors (Fasula et al., 2013). The formative assessment was used to revise the curriculum to address synergism of risk factors, substance abuse, trauma, mental health, empowerment and relationship power (Fasula et al., 2013).

Sistering, Informing, Healing, Living and Empowering (SiHLE) is a program that targets sexually experienced African American adolescent females (Compendium of Evidence-Based Interventions and Best Practices for HIV Prevention, 2014). The goals of this intervention are to reduce risky sexual behavior, reduce STIs and pregnancies, and increase condom use and HIV knowledge through demonstrations, group discussions, lectures, and roleplaying activities (Compendium of Evidence-Based Interventions and Best Practices for HIV Prevention, 2014). The intervention is comprised of four sessions; each session of four hours is delivered one day per week for an intervention duration of one month (DiClemente et al., 2004). The SiHLE study is powered at 0.80 , which is based on a projected effect size of $50 \%$ for increased condom use and a type I error at 0.05 for a two-tailed test.

The study required 250 participants and recruited 522, who were randomized into either an intervention (251 participants) or a control group (271 participants) (DiClemente et al., 2004). Participants of SiHLE reported greater consistency in condom use and fewer new vaginal sex partners (Compendium of Evidence-Based Interventions and Best Practices for HIV Prevention, 2014). Further, over the 12-month follow-up period, SiHLE participants were less likely to acquire new chlamydia infections than females in the comparison group (Compendium of Evidence-Based Interventions and Best Practices for HIV Prevention, 2014). These interventions demonstrated effectiveness in regard to increased knowledge and protective behaviors, as well as decreases in risk-taking and cases of STIs.

\section{CONCLUSIONS}

As Georgia continues to struggle with the crisis of STIs, particularly gonorrhea and chlamydia, which are more prevalent among adolescents than HIV, effective education of youth about these diseases will be essential. Sexual health education in Georgia appears to lean toward prevention, which should be a component, but not constitute the entire approach. Emerging data indicate that many citizens of our state are ill-equipped educationally to make informed decisions in regard to health risks and protective behaviors related to STIs. The data suggest that we assess the present knowledge about STIs of health educators, particularly those whose preparation for teaching did not include sexual health. Many educators in Georgia consider that they need further information to teach STI/HIV prevention and human sexuality. But, many of these educators also may need additional professional development beyond STI/HIV prevention. Sexual health education, including that for HIV/AIDS, is essential to curtail this crisis, but these educational endeavors must be culturally sensitive (Osemene, Essien, \& Egbunike, 2001) as well as evidencebased.

We recommend that departments charged with educating Georgia's youth assess what their students know about STIs/HIV, including their etiology, health effects and transmission. The Departments of Education and Juvenile Justice in Georgia are leaders in the area of education for students and youth who have been detained, but other departments, such as the Department of Public Health, contribute substantially to educating the public about health. By knowing more about the populations at high risk, these departments may be more effective in their approach to STI/HIV education. STI research, including investigations in regard to knowledge, attitudes, and behaviors, should be an ongoing and a collaborative component of efforts to reduce and prevent these diseases.

We anticipate that interventions based on risk reduction including education, will undergo continual changes to meet the needs of different generational cohorts (e.g., curricula and interventions effective with Millennials, who were born between the 1980s and early 2000s, may be less effective with the succeeding Generation Z). Changes in technology, social media, and the ways in which different generations respond will be factors in developing and implementing interventions specific for various populations and settings (e.g., schools, detention/corrections, clinical settings and health departments).

Since the rates and prevalence of STIs are not proportionately distributed across the state (County Health Rankings \& Roadmap, 2015), the basis for this should be investigated to understand community-level risk and to provide protective factors, including sexual health education and health resources.

Education and research contribute importantly to reducing the number of cases and preventing the transmission of STIs; however, we propose a broader and more global approach. A question is: How do Georgia's Departments of Education, Public Health, Corrections, Juvenile Justice, Community Health, and other state agencies collaborate to address the STI crisis in our state? An effective multidepartmental strategy will require unified messages and curricula that are evidence-based and population-specific (i.e., one approach may not be effective across all groups or settings). This broader approach to preventing and reducing STIs will also entail abandoning silo-based strategies, in which departments address issues narrowly, utilizing expertise and resources unique to their agencies. Although some school boards and agencies may be protective of local autonomy, implementation of evidence-based STI messages and curricula does not mean loss of control. Local efforts should be informed by evidence.

Acknowledgements: This work was supported by a pilot grant from the Institute of Public and Preventive Health at Georgia Regents University. 


\section{References}

Ballonoff Suleiman, A., Johnson, M., Shirtcliff, E. A., \& Galvan, A. (2015). School-based sex education and neuroscience: What we know about sex, romance, marriage, and adolescent brain development. J Sch Health, 85(8), 567-574.

Barge, J. D. (2014). Georgia Student Health Survey II. Atlanta, GA: Georgia Department of Education.

Barr, E. M., Goldfarb, E. S., Russell, S., Seabert, D., Wallen, M., \& Wilson, K. L. (2014). Improving sexuality education: The development of teacher-preparation standards. J Sch Health, 84(6), 396-415.

Borawski, E. A., Tufts, K. A., Trapl, E. S., Hayman, L. L., Yoder, L. D., \& Lovegreen, L. D. (2015). Effectiveness of health education teachers and school nurses teaching sexually transmitted infections/human immunodeficiency virus prevention knowledge and skills in high school. J Sch Health, 85(3), 189-196.

Braxton, J., Carey, D., Davis, D., Flagg, E., Footman, A., Grier, L., ... Weinstock, H. (2014). Sexually Transmitted Disease Surveillance 2013. Atlanta, GA: U.S. Department of Health and Human Services Retrieved from http://www.cdc.gov/std/stats13/surv2013-print.pdf.

Compendium of Evidence-Based Interventions and Best Practices for HIV Prevention. (2014). Atlanta, GA: Centers for Disease Control and Prevention Retrieved from http://www.cdc.gov/hiv/prevention/research/compendium/rr/co mplete.html.

County Health Rankings \& Roadmap. (2015). Sexually Transmitted Infections in Georgia. Retrieved 2015, November, 11 from

http://www.countyhealthrankings.org/app/georgia/2015/measure /factors/45/map.

Cox, K. (2010). Georgia Performance Standards for Health Education. Atlanta, GA: Georgia Department of Education.

Danielson, C. K., Walsh, K., McCauley, J., Ruggiero, K. J., Brown, J. L., Sales, J. M., . . Diclemente, R. J. (2014). HIVRelated Sexual Risk Behavior Among African American Adolescent Girls. J Womens Health (Larchmt) 23(5). 413-419.

DiClemente, R. J., Davis, T. L., Swartzendruber, A., Fasula, A. M., Boyce, L., Gelaude, D., . . . Staples-Horne, M. (2014). Efficacy of an HIV/STI Sexual Risk-Reduction Intervention for African American Adolescent Girls in Juvenile Detention Centers: A Randomized Controlled Trial. Women Health, 54(8), 726-749.

DiClemente, R. J., Wingood, G. M., Harrington, K. F., Lang, D. L., Davies, S. L., Hook, E. W., . . Robillard, A. (2004). Efficacy of an HIV prevention intervention for African American adolescent girls: A randomized controlled trial. JAMA, 292(2), 171-179.

Falb, M., Figueroa, A., \& Kanny, D. (2007). 2006 Georgia School Health Profi les Report. (DPH07/027.HW). Atlanta, GA: Georgia Department of Human Resources, Division of Public Health, Chronic Disease, Injury, and Environmental Epidemiology Section.

Fasula, A. M., Fogel, C. I., Gelaude, D., Carry, M., Gaiter, J., \& Parker, S. (2013). Project power: Adapting an evidence-based HIV/STI prevention intervention for incarcerated women. AIDS Educ Prev, 25(3), 203-215.
Fonner, V. A., Armstrong, K. S., Kennedy, C. E., O'Reilly, K. R., \& Sweat, M. D. (2014). School based sex education and HIV prevention in low- and middle-income countries: A systematic review and meta-analysis. PLoS One, 9(3), e89692.

Georgia Division of Family and Children Services. (2015). Abstinence Education Program. Retrieved from http://dfcs.dhs.georgia.gov/abstinence-education-program

Herrman, J. W., \& Waterhouse, J. K. (2012). A pilot program to address healthy sexual behaviors among girls in juvenile detention. J Child Adolesc Psychiatr Nur, 25(4), 224-231.

In-Iw, S., Braverman, P. K., Bates, J. R., \& Biro, F. M. (2015). The Impact of Health Education Counseling on Rate of Recurrent Sexually Transmitted Infections in Adolescents. $J$ Pediatr Adolesc Gynecol 28(6):481-485 .

LeFevre, M. L. (2014a). Behavioral counseling interventions to prevent sexually transmitted infections: U.S. PreventiveServices Task Force recommendation statement. Ann Intern Med, 161(12), 894-901.

LeFevre, M. L. (2014b). Screening for chlamydia and gonorrhea: U.S. Preventive Services Task Force recommendation statement. Ann Intern Med, 161(12), 902-910.

Ma, Z. Q., Fisher, M. A., \& Kuller, L. H. (2014). School-based HIV/AIDS education is associated with reduced risky sexual behaviors and better grades with gender and race/ethnicity differences. Health Educ Res, 29(2), 330-339.

Morrison-Beedy, D., Jones, S. H., Xia, Y., Tu, X., Crean, H. F., \& Carey, M. P. (2013). Reducing sexual risk behavior in adolescent girls: Results from a randomized controlled trial. $J$ Adolesc Health, 52(3), 314-321.

Osemene, N., Essien, E., \& Egbunike, I. (2001). HIV/AIDS behind bars: An avenue for culturally sensitive interventions. Journal of the National Medical Association, 93(12), 481-486.

Reif, S. S., Whetten, K., Wilson, E. R., McAllaster, C., Pence, B. W., Legrand, S., \& Gong, W. (2014). HIV/AIDS in the Southern USA: A disproportionate epidemic. AIDS Care, 26(3), 351-359.

Rosenberg, H. J., Vance, J. E., Rosenberg, S. D., Wolford, G. L., Ashley, S. W., \& Howard, M. L. (2014). Trauma exposure, psychiatric disorders, and resiliency in juvenile-justice-involved youth. Psychological Trauma: Theory, Research, Practice, and Policy, 6(4), 430-437.

Schalet, A. T., Santelli, J. S., Russell, S. T., Halpern, C. T., Miller, S. A., Pickering, S. S., . . Hoenig, J. M. (2014). Invited commentary: Broadening the evidence for adolescent sexual and reproductive health and education in the United States. $J$ Youth Adolesc, 43(10), 1595-1610.

Sex education and AIDS prevention instruction, Official Code of Georgia Annotated § 20-2-143 (1998).

Stanger-Hall, K. F., \& Hall, D. W. (2011). Abstinence-only education and teen pregnancy rates: Why we need comprehensive sex education in the U.S. PLoS One, 6(10), e24658.

Vital signs: HIV testing and diagnosis among adults--United States, 2001-2009. (2010). MMWR Morb Mortal Wkly Rep, 59(47), 1550-1555.

Zhang, S., McGoy, S. L., Dawes, D., Fransua, M., Rust, G., \& Satcher, D. (2014). The potential for elimination of racial-ethnic disparities in HIV treatment initiation in the Medicaid population among 14 southern states. PLoS One, 9(4), e96148 